\title{
Bimbingan Teknis Pengadaan Desain dan Rencana Anggaran Biaya TPQ Pasir Putih Malang
}

\author{
Sumardi $^{1}$, Fauzi Akbar Rahmawan ${ }^{2}$, Indah Ria Riskiyah ${ }^{3}$, Utami Retno Pudjowati ${ }^{4}$ \\ 1,2,3,4 Jurusan Teknik Sipil, Politeknik Negeri Malang \\ ${ }^{1}$ sumardi.polinema@gmail.com, ${ }^{2}$ fauziakbar@polinema.ac.id, ${ }^{3}$ indahria@polinema.ac.id, \\ utami.retno@polinema.ac.id
}

\begin{abstract}
Abstrak
Taman Pendidikan Al-quran (TPQ) Pasir Putih yang berlokasi di Jl. Pasir putih Kota Malang merupakan salah satu fasilitas pendidikan nonformal untuk anak-anak yang memiliki peran penting bagi pengembangan pendidikan agama Islam bagi anak. Sebagai fasilitas pendidikan nonprofit yang dibiayai secara sukarela, maka perawatan dan pembangunan membutuhkan bantuan donatur atau masyarakat sekitar dalam prosesnya. Sehingga permasalahan yang dihadapi perlu mendapat perhatian bukan hanya dari pengelola, namun juga masyarakat. Metode yang digunakan dalam pengabdian ini adalah dengan wawancara dan survey kondisi TPQ. Berdasarkan hasil survey dan wawancara, pengelola merasa perlu menambah beberapa fasilitas seperti banner tata cara sholat dengan ukuran besar, pengecatan ruangan, mendesain interior ruangan yang lebih nyaman dan pengecatan fasilitas bermain. Seluruh fasilitas tersebut membutuhkan desain yang sesuai kebutuhan dengan estimasi anggaran agar dapat di ajukan kepada donatur jika akan di kerjakan. Berdasarkan hasil desain dan perhitungan didapat Rencana Anggaran Biaya sebesar Rp. 3.952.500.
\end{abstract}

Kata kunci : TPQ, rencana anggaran biaya, desain

\section{PENDAHULUAN}

\subsection{Latar Belakang}

Taman Pendidikan Quran (TPQ) merupakan fasilitas pendidikan keagamaan nonformal untuk anak-anak yang memiliki peran penting bagi pengembangan pendidikan agama Islam pada anak. Disini anak-anak atau siswa akan belajar membaca alquran dan belajar doa-doa yang bermanfaat untuk pendidikan spiritualnya. Para siswa akan berkumpul pada jam setelah sholat ashar dan belajar membaca surat pendek serta terkadang bermain bersama di fasilitas TPQ tersebut agar pendidikan agama tidak terkesan membosankan. Kegiatan keagamaan seperti pengajian dan persiapan takbiran saat hari raya juga menjadi agenda rutin yang dilaksanakan TPQ [1].

Berbagai peran penting yang dilakukan TPQ tentunya membutuhkan dukungan fasilitas yang memadai agar kegiatan siswa dapat berjalan dengan baik. Selama ini fasilitas yang dibangun seperti ruang kelas dan fasilitas bermain menjadi tanggungan masyarakat atau donatur tertentu dikarenakan pendidikan ini merupakan organisasi nonprofit yang tidak membebankan biaya pendidikan kepada orangtua siswa. Karena kondisi tersebut, kondisi fisik bangunan terkadang tidak terawat jika tidak ada masyarakat yang menggerakkan untuk melakukan perbaikan.

Kondisi TPQ seperti ini banyak di alami oleh beberapa TPQ yang ada di Kota Malang, tidak terkecuali TPQ Pasir Putih, yang lokasinya terletak di kota Malang, tepatnya di Jl. Pasir putih Kelurahan Lowokwaru Malang. TPQ yang berdiri di salah satu bagian rumah warga ini, telah berdiri sejak tahun 2004 dan telah banyak mencetak lulusan sehingga dapat mengaji. Kelas untuk belajar mengaji dimulai dari jam 15.00 WIB sampai 17.00 WIB dengan jadwal santri putra dan santri putri bergantian lain hari.

Untuk mengetahui secara langsung permasalahan yang terjadi di lapangan maka dilakukan kunjungan ke TPQ Pasir Putih ini. Berdasarkan hasil survey dan wawancara dapat diketahui kondisi sebenarnya seperti ditunjukkan pada Gambar 1 sampai Gambar 5. 


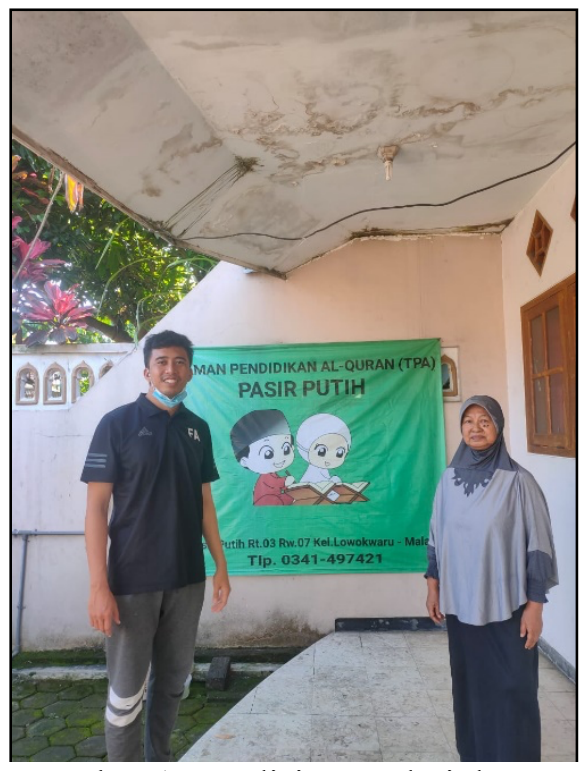

Gambar 1 Kondisi TPQ dari depan

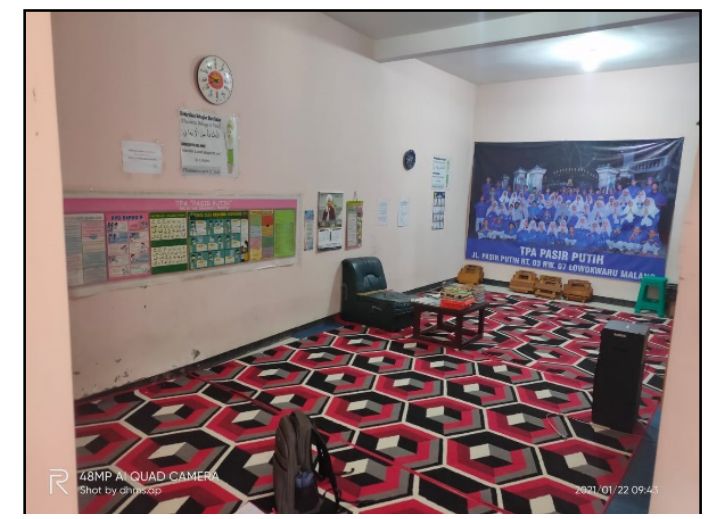

Gambar 2 Kondisi dalam TPQ sebelum perbaikan

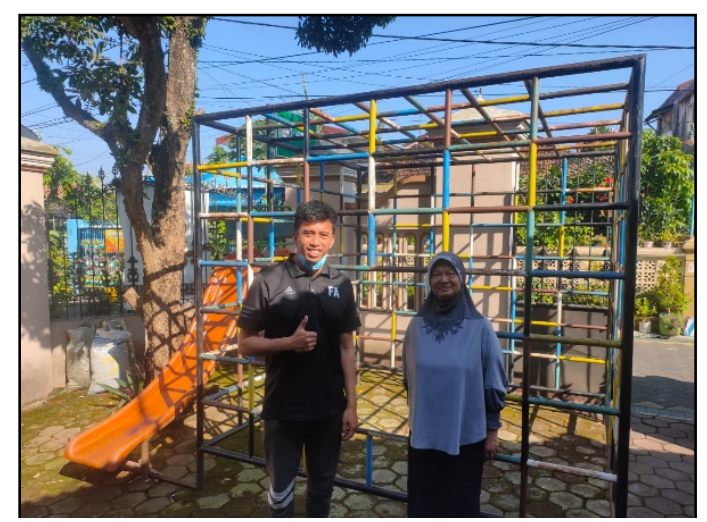

Gambar 3 Kondisi fasilitas bermain dengan cat yang memudar

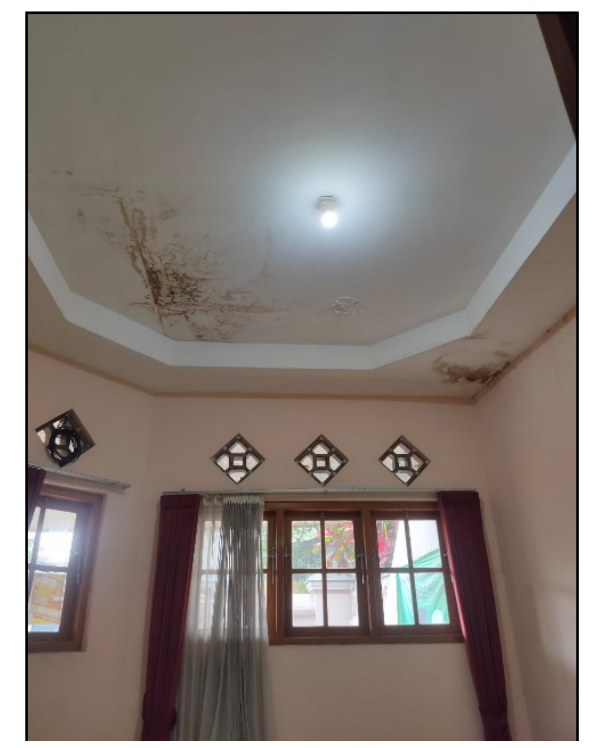

Gambar 4 Kondisi plafon yang berjamur

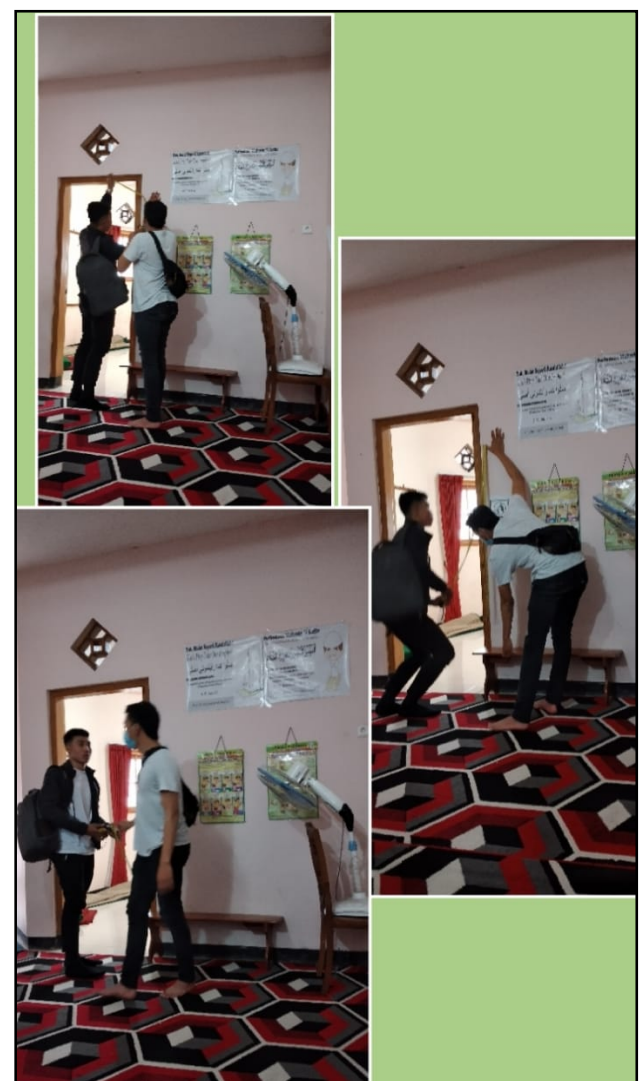

Gambar 5 Pengukuran Dinding untuk Banner

Berdasarkan hasil pengamatan terdapat kondisi fisik bangunan yang cukup memprihatinkan. Kondisi yang dapat dilihat pada TPQ Pasir Putih ini yang paling parah adalah plafon yang meninggalkan bercak karena rembesan air. Selain itu pembangunan TPQ yang sudah berumur lebih dari 10 tahun ini memiliki tampilan cat yang mulai memudar, baik di 
bagian dinding dalam dan luar bangunan, selain itu fasilitas bermain juga mulai berkarat karena lapisan cat yang mulai terkelupas. Pengelola juga mengeluhkan ukuran mading yang berisi doa-doa terlalu kecil, sehingga jika santri diminta untuk membaca dan menghafalkan, harus dilakukan secara bergantian.

\subsection{Permasalahan}

Permasalahan yang dihadapi secara umum dapat di uraikan sebagai berikut:
a. Cat dinding dalam dan luar memudar
b. Plafon meninggalkan bekas air
c. Fasilitas permainan mulai berkarat
d. Tulisan doa-doa terlalu kecil
e. Estimasi biaya perbaikan fasilitas fisik

\subsection{Tujuan}

Tujuan dari kegiatan pengabdian pada TPQ Pasir Putih, Jl. Pasir putih Kelurahan Lowokwaru Malang adalah:

a. Turut serta dalam upaya peningkatan kualitas santri melalui kenyamanan fasilitas fisik

b. Pemberian bantuan desain dan perbaikan fisik serta banner berisi doa sehari hari

c. Meningkatkan kenyamanan dalam aktivitas TPQ bagi santri dan juga guru yang mengajar

\subsection{Manfaat}

Manfaat dari kegiatan pengabdian pada TPQ

Pasir Putih, di Jl. Pasir putih Kelurahan Lowokwaru Malang adalah:

a. Santri TPQ dan warga dapat menggunakan fasilitas dengan nyaman

b. Membantu keterbatasan dana yang dihadapi oleh pengelola dalam menjaga fasilitas TPQ

c. Meningkatkan minat anak-anak untuk datang ke TPQ dengan fasilitas bermain yang telah diperbaharui

\section{METODE} meliputi:

Metode yang digunakan dalam PPM ini

a. Survey lapangan

Untuk memahami kondisi fisik bangunan dan jenis perbaikan apa yang diperlukan, maka dilakukan kunjungan dan survey lokasi PPM. Survey ini dilakukan dengan menganalisa pula jenis material yang dibutuhkan untuk melakukan perbaikan.

b. Wawancara
Wawancara dilakukan dengan menemui pihak pengelola dan menanyakan kendala yang dialami selama ini dan dicarikan solusi untuk perbaikannya.

c. Desain dan estimasi

Setelah melakukan survey di lokasi kegiatan dan wawancara terhadap pengelola, maka dilakukan desain ruangan, desain banner, serta estimasi biaya yang dikeluarkan untuk melakukan perbaikan sesuai yang direncanakan [2].

\section{HASIL DAN PEMBAHASAN}

Observasi dilakukan oleh tim PPM Polinema dengan menemui pengelola TPQ yaitu ibu Ninik Chairani. Pada pertemuan ini dibahas beberapa hal terkait letak pemasangan banner, serta bagian fisik bangunan yang perlu diperbaiki. Hasil pertemuan ini adalah kebutuhan pembuatan banner berukuran jumbo agar dapat terlihat oleh banyak santri dalam waktu bersamaan.

Setelah dilakukan analisa, maka diputuskan desain banner untuk tata cara sholat, doa sehari hari, dan tulisan asmaul husna sebagaimana pada Gambar 6 dan Gambar 7.

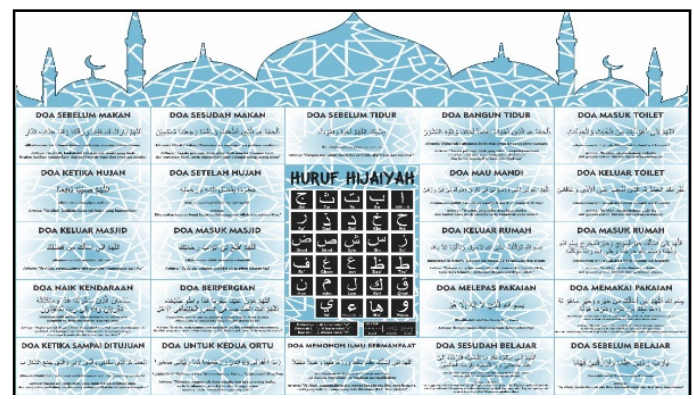

Gambar 6 Desain banner doa sehari-hari

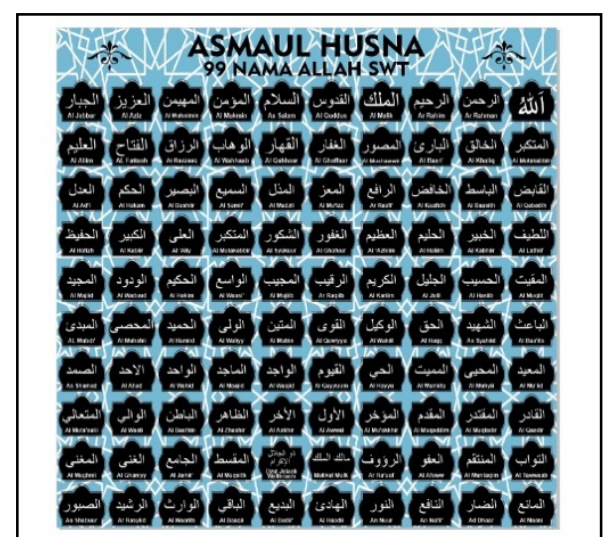

Gambar 7 Desain banner Asmaul Husna

Selanjutnya untuk memberikan informasi gambaran kebutuhan RAB dalam melakukan 
perbaikan fisik berupa pengecatan dapat dihitung RAB dengan hasil pada Tabel 1 berikut [3]:

Tabel 1 rencana anggaran biaya

\begin{tabular}{|r|l|r|r|r|r|}
\hline No & Uraian Kegiatan & Vol. & Sat. & $\begin{array}{c}\text { Harga } \\
\text { Satuan }\end{array}$ & Harga \\
\hline 1 & $\begin{array}{l}\text { Pengecatan besi } \\
\text { fasilitas bermain } \\
\text { anak }\end{array}$ & 20 & $\mathrm{~m} 2$ & 32,000 & 640,000 \\
\hline 2 & Pengecatan plafond & 35 & $\mathrm{~m} 2$ & 27,500 & 962,500 \\
\hline 3 & Pengecatan dinding & 76 & $\mathrm{~m} 2$ & 25,000 & $1,900,000$ \\
\hline 4 & Pengadaan banner & 20 & $\mathrm{~m} 2$ & 22,500 & 450,000 \\
\hline \multicolumn{4}{|c|}{ Total } & $\mathbf{3 , 9 5 2 , 5 0 0 . 0 0}$ \\
\hline
\end{tabular}

Setelah mengetahui hasil perhitungan $\mathrm{RAB}$ dalam perbaikan fisik, maka mulai dilakukan perbaikan dan pengadaan banner untuk media pembelajaran santri. Dimana pekerjaan fisik pengecatan dapat diselesaikan dalam waktu satu minggu dan pengadaan banner dalam waktu dua minggu.

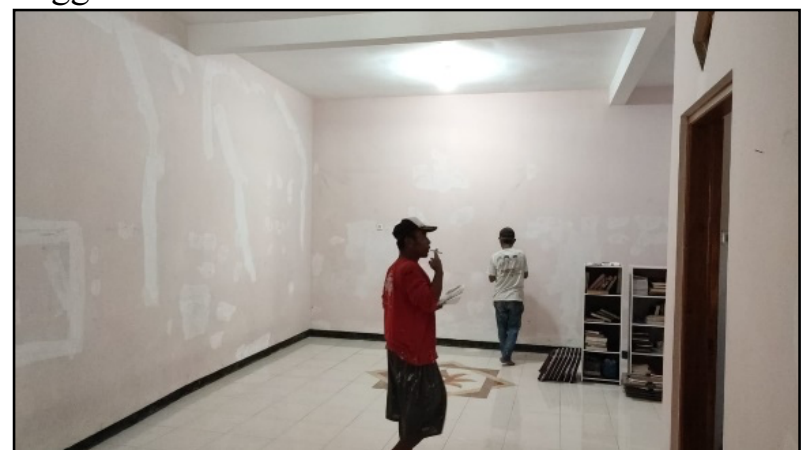

Gambar 8 Proses pengecatan dinding

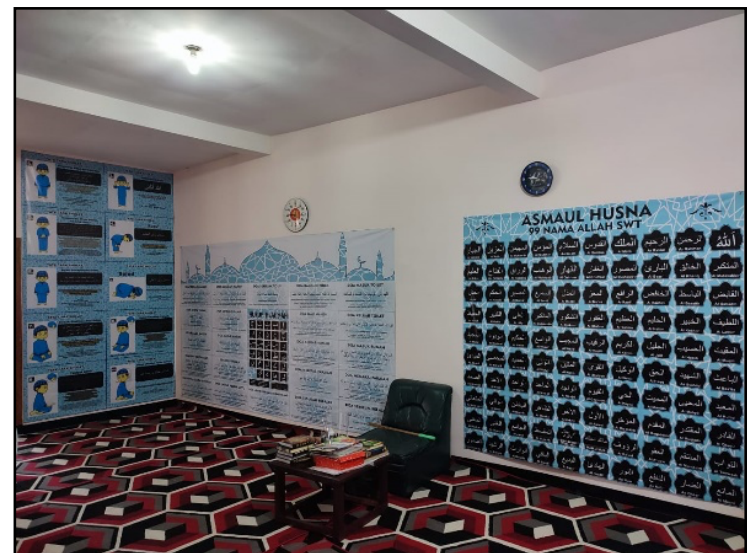

Gambar 9 Pemasangan banner

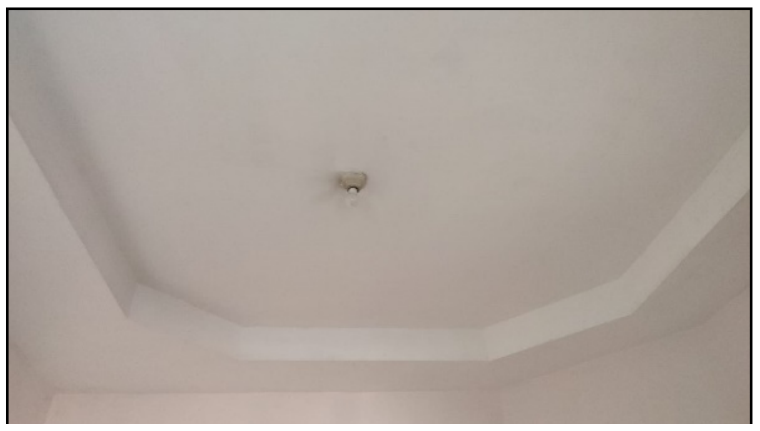

Gambar 10 Kondisi plafon setelah pengecatan

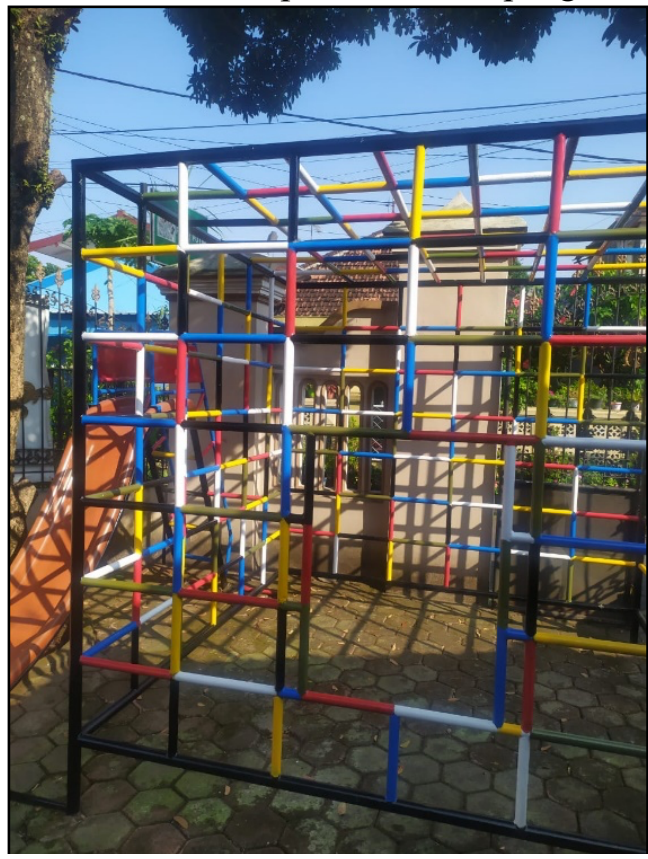

Gambar 11 Fasilitas bermain setelah pengecatan

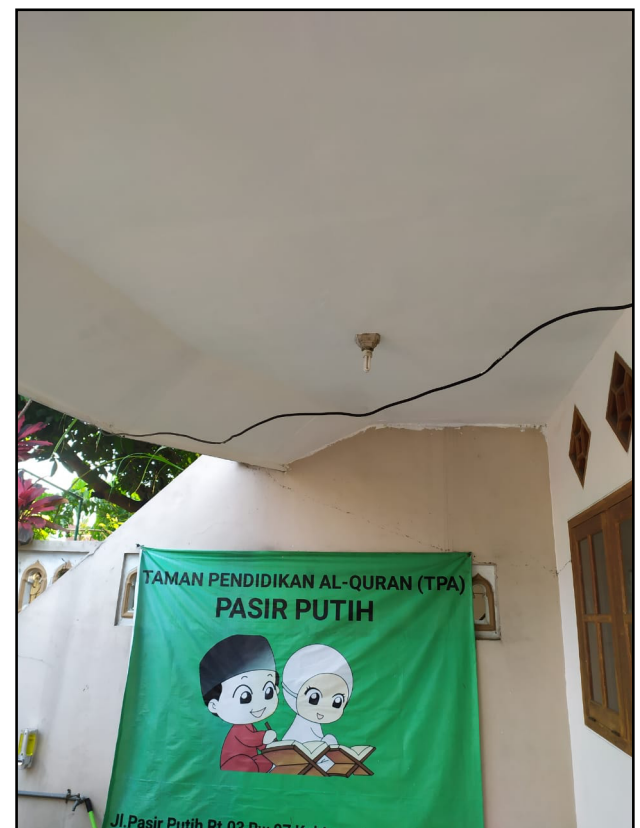

Gambar 12 Plafon bagian depan TPQ setelah pengecatan 
Hasil desain dan diskusi disesuaikan kondisi di lapangan, dimana cat dinding menggunakan warna pink muda dengan kebutuhan cat 1 pil, Cat plafond berwarna putih dengan kebutuhan $10 \mathrm{~kg}$, cat besi untuk fasilitas bermain anak menggunakan 5 warna yang berbeda masing-masing membutuhkan $5 \mathrm{~kg}$ cat. Pada banner menggunakan tema warna biru cerah agar warna mencolok dan ukuran banner menyesuaikan ukuran dinding ruangan.

\section{KESIMPULAN}

Beberapa kesimpulan yang dapat diambil pada kegiatan Pengabdian Kepada Masyarakat di TPQ Pasir Putih Kota Malang ini adalah:

a. Kegiatan PPM dilakukan dengan mendesain sekaligus pengadaan banner kumpulan doa dan bimbingan teknis serta bantuan untuk pengecatan fasilitas TPQ.

b. Didapat estimasi Rencana Anggaran Biaya sebesar Rp. 3.952.000 jika pengelola ingin melanjutkan perbaikan seluruh fisik bangunan yang di inginkan.

c. Hasil kegiatan PPM ini membuat para santri lebih termotivasi belajar dengan sarana dan fasilitas yang lebih memadai.

\section{SARAN}

antara lain:

Beberapa saran yang dapat disampaikan

a. Pelaksanaan PPM yang bersifat pembangunan fisik bangunan sebaiknya melibatkan beberapa donatur atau tenaga dari masyarakat sekitar agar mendapatkan hasil maksimal,

b. Agar kondisi fisik dapat terjaga dengan baik, santri perlu di edukasi untuk menjaga fasilitas yang sudah dimiliki.

\section{UCAPAN TERIMA KASIH}

Ucapan terimakasih disampaikan kepada pihak yang terlibat dalam kegiatan ini yaitu:

a. Dana DIPA Politeknik Negeri Malang Nomor SP DIPA-042.01.2.401004/2021 yang telah membantu pendanaan pada kegiatan ini,

b. Yayasan pendidikan Al-Quran Pasir Putih atas kerjasama selama pelaksanaan kegiatan Pengabdian Kepada Masyarakat,

c. Seluruh tim PPM yang bekerja keras dalam penyelesaian kegiatan ini,

d. Serta seluruh pihak yang terlibat dan tak bisa disebutkan satu persatu.

\section{DAFTAR PUSTAKA}

[1] Amrullah, U. S., 2019, Pengadaan Fasilitas Olahraga Badminton bagi Taman Pendidikan Al-Quran Ahlussunah Waljama'ah RT 05 RW 03 Kel. Tlogomas Lowokwaru Malang, Jurnal Pengabdian Polinema Kepada Masyarakat, Politeknik Negeri Malang, Malang.

[2] Ervianto, Wulfram I., 2013, Manajemen Proyek Konstruksi Edisi Revisi, Andi Offset, Jakarta.

[3] Zukarnain, I., 2011, Rencana Anggaran Biaya, http://iskandarzulkarnainpolinema.blogspot.com 12011/03/bab-1-rencana-anggaran-biaya.html. 